Br Heart F 1982; 48: 306

\title{
Oxford pacemaker infection trial
}

Sir,

We read with interest the Oxford pacemaker infection trial. This came at a time when we in Leeds were conducting a similar prospective investigation into the effect of antibiotics on pacemaker infections. Our trial consisted of 67 patients who had satisfied the exclusion criteria. The latter were essentially similar to those in the Oxford trial but also excluded diabetics from randomisation as we felt there was enough evidence showing that these patients have an increased predisposition to staphylococcal infections. Of the 67 patients in the trial, there was one infection in the treated and one in the untreated group.

We think that the Oxford data are convincing. For those still doubting this evidence, antibiotic prophylaxis must remain mandatory for the at-risk patients undergoing early re-exploration of their generator pockets. We also consider diabetics to be at increased risk of staphylococcal infection and woulc always advocate the use of antibiotics in this group.

\section{A Young,}

Department of Cardiovascular Medicine,

East Birmingham Hospital, Bordesley Green East, Birmingham B9 5ST.

D R Smith, Leeds General Infimary, Great George Street, Leeds. 